\title{
Caracterização do gene vip3A e toxicidade da proteína Vip3Aa50 à lagarta-do-cartucho e à lagarta-da-soja
}

\author{
Camila Soares Figueiredo(1), Suzana Cristina Marucci(1), Renata Izabel Dozzi Tezza(1), \\ Manoel Victor Franco Lemos $^{(1)}$ e Janete Apparecida Desidério(1)
}

\footnotetext{
(1)Universidade Estadual Paulista Júlio de Mesquita Filho, Avenida Paulo Donato Castellane s/no, CEP 14884-900 Jaboticabal, SP. E-mail: camila_sfigueiredo@hotmail.com, suzy_marucci@yahoo.com.br, renata25@fcav.unesp.br, mvictor@fcav.unesp.br, janete@fcav.unesp.br
}

\begin{abstract}
Resumo - O objetivo deste trabalho foi caracterizar o gene vip3A de Bacillus thuringiensis e verificar a toxicidade da proteína Vip3Aa50 a larvas da lagarta-do-cartucho (Spodoptera frugiperda) e da lagarta-da-soja (Anticarsia gemmatalis). O gene vip3A foi amplificado por PCR, com iniciadores específicos, e gerou um fragmento de $2.370 \mathrm{pb}$. Esse fragmento foi clonado em vetor pGEM-T Easy e, em seguida, sequenciado, subclonado em vetor de expressão pET-28a (+) e inserido em células de Escherichia coli BL21 (DE3). A expressão da proteína Vip3Aa50 foi induzida por isopropil- $\beta$-D-1-tiogalactopiranosídeo (IPTG), visualizada em SDS-PAGE e detectada por "Western blot". Os ensaios de toxicidade revelaram alta atividade da proteína Vip3Aa50 contra as larvas neonatas da lagarta-da-soja e da lagarta-do-cartucho, com $\mathrm{CL}_{50}$ de 20,3 e 79,6

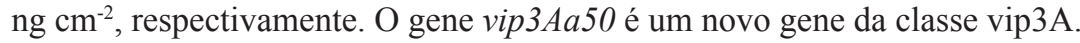

Termos para indexação: Anticarsia gemmatalis, Spodoptera frugiperda, controle biológico, expressão heteróloga, proteína inseticida vegetativa.

\section{Characterization of the vip3A gene and toxicity of Vip3Aa50 protein to fall armyworm and velvetbean caterpillar}

\begin{abstract}
The objective of this work was to characterize the vip3A gene of Bacillus thuringiensis and to evaluate the toxicity of Vip3Aa50 protein to the fall armyworm (Spodoptera frugiperda) and velvetbean caterpillar (Anticarsia gemmatalis) larvae. The gene vip $3 A$ was amplified by specific PCR primers, generating a 2,370-bp fragment. This fragment was cloned into the pGEM-T Easy vector, and then it was sequenced, subcloned into the pET-28a (+)'s expression vector, and inserted into Escherichia coli BL21 (DE3) cells. The Vip3Aa50 protein expression was induced by isopropyl- $\beta$-D-1-thiogalactopyranoside (IPTG), visualized in SDS-PAGE, and detected by Western blot. The toxicity bioassay showed a high activity of Vip3Aa50 protein against both velvetbean and fall armyworm neonate larvae, with $\mathrm{LC}_{50}$ at 20.3 and $79.6 \mathrm{ng} \mathrm{cm}^{-2}$ respectively. The vip 3 Aa 50 gene, is a new gene of vip3A class.
\end{abstract}

Index-terms: Anticarsia gemmatalis, Spodoptera frugiperda, biological control, heterologous expression, vegetative insecticidal protein.

\section{Introdução}

A bactéria Bacillus thuringiensis Berliner é amplamente utilizada no controle biológico, há mais de 50 anos (Monnerat \& Bravo, 2000). Os produtos comerciais disponíveis baseiam-se em d-endotoxinas (proteínas Cry), sintetizadas durante a esporulação, e em proteínas sintetizadas durante a fase vegetativa de B. thuringiensis (Fiúza \& Berlitz, 2009).

As proteínas inseticidas vegetativas (Vip) apresentam enorme potencial inseticida contra pragas insensíveis ou resistentes às proteínas Cry, pois atuam em receptores diferentes no intestino médio do inseto (Lee et al., 2006). Essas proteínas são secretadas em forma solúvel e apresentam toxicidade a insetos de importância agronômica (Liu et al., 2007). As toxinas binárias, Vip1 e Vip2 atuam no controle de algumas espécies das ordens Coleoptera (Warren, 1997) e Hemiptera (Sampurna \& Maiti, 2011); as proteínas da família Vip3A controlam algumas espécies da ordem Lepidoptera (Estruch et al., 1996). Até o momento, não foram localizados relatos na literatura sobre a ação inseticida da proteína Vip4.

A lagarta-da-soja, Anticarsia gemmatalis, e a lagarta-do-cartucho, Spodoptera frugiperda, lepidópteros da família Noctuidae, são importantes pragas desfolhadoras da cultura da soja (Glycine max) e do milho (Zea maiz) (Mendes et al., 2008; Mendonça 
et al., 2011), respectivamente. O controle destes insetos tem sido feito basicamente com o uso de inseticidas sintéticos e de espécies transgênicas que expressem proteínas tóxicas, especialmente as proteínas Cry. As lagartas de $S$. frugiperda têm apresentado alta suscetibilidade às toxinas da classe Vip3A (Sena et al., 2009); porém, o efeito destas proteínas a lagartas da espécie $A$. gemmatalis ainda não foi descrito.

O objetivo deste trabalho foi caracterizar o gene vip3A de $B$. thuringiensis e verificar a toxicidade da proteína Vip3Aa50 a larvas de lagarta-do-cartucho e lagarta-da-soja.

\section{Material e Métodos}

Utilizou-se o isolado I131 de B. thuringiensis, da coleção do Laboratório de Genética de Bactérias e Biotecnologia Aplicada da Unesp (Jaboticabal, SP). O gene vip3 foi caracterizado por PCR, com iniciadores específicos (Tabela 1) descritos por Loguercio et al. (2002). Para verificar a presença do gene vip3A no isolado I131, foram utilizadas, como controles, as linhagens $B$. thuringiensis var. tolworthi HD-125 (produtora da toxina lepidóptero-específica) e $B$. thuringiensis var. tenebrionis (toxina coleópteroespecífica), provenientes do Bacillus Genetics Stock Center, Columbus, Ohio. A linhagem padrão lepidóptero-específica $B$. thuringiensis var. tolworthi HD-125, apresenta o gene vip3A e foi utilizada para verificar o perfil de amplificação do gene vip $3 A$ do isolado I131 nas reações de PCR (Tabela 1). O

Tabela 1. Iniciadores utilizados no sequenciamento do gene vip3A do isolado I131 de Bacillus thuringiensis.

\begin{tabular}{lcc}
\hline Iniciador & Sequência & Nucleotídeo \\
\hline VIP5 $^{(1)}$ & direta & ATG ACC AAG AAT AAT ACT AAA TTA AGC \\
VIP2 $^{(1)}$ & reversa & TCT GGG CAC AAT AAT TTA TCC \\
VIP3 $^{(1)}$ & direta & CAG GAC ATG CAT TGA TTG G \\
VIP6 $^{(1)}$ & reversa & GAT CTT ACT TAA TAG AGA CAT CG \\
V1R $^{(1)}$ & reversa & GCA GGT GTA ATT TCA GTA AGT GTA GAG \\
61BF & direta & CTC TAT GTT GAG TGA TGT AAT \\
61BR & reversa & TCC GAC CTC ACT GCC ACT TG \\
61CR & reversa & TGA TCC CGT ACT CGT CC \\
61DF & direta & CGG AGA TGC TAA TGT AAG G \\
P1F(3) $^{(2)}$ & direta & CCC TAC ACT TTC TAA TAC \\
P2R $^{(3)}$ & reversa & CCG CTT CAC TTG ATT CTA C \\
T7 & direta & TAA TAC GAC TCA CTA TAG GG \\
SP6 & reversa & ATT TAG GTG ACA CTA TAG \\
\hline
\end{tabular}

(1)Loguercio et al. (2002); (2)Marucci (2010); ${ }^{(3)}$ no presente trabalho. controle coleóptero-específico, B. thuringiensis var. tenebrionis, foi utilizado como controle negativo. Como esta linhagem foi previamente caracterizada como não portadora do gene vip $3 A$, não foi observado produto amplificado, comprovando que os iniciadores somente amplificariam o gene vip $3 A$.

$\mathrm{O}$ isolado $\mathrm{e}$ as duas linhagens-padrão foram multiplicados em placas de Petri, com o meio de cultura "brain heart infusion broth" (BHIB) (HiMedia Laboratories Pvt., Ltd., Mumbai, India), a $30^{\circ} \mathrm{C}$, por 16 horas. Colônias isoladas foram inoculadas em $2 \mathrm{~mL}$ de meio de cultura $\mathrm{BHIB}$ e mantidas a $30^{\circ} \mathrm{C}$, em agitação de $200 \mathrm{rpm}$, por 16 horas.

O DNA do isolado e das linhagens-controle foi extraído pelo método de fervura (Letowski et al., 2005) e submetido à amplificação do gene vip $3 A$, com os iniciadores vip5 e vip6 (Tabela 1), à temperatura de anelamento de $53^{\circ} \mathrm{C}$, com a enzima "Platinum Taq DNA_polymerase high fidelity" (Invitrogen Brasil, Ltda., São Paulo, SP, Brasil). A PCR foi realizada em volume total de $25 \mu \mathrm{L}$, com: $150 \mathrm{ng}$ de DNA, $1 \mathrm{U}$ de enzima "Platinum Taq DNA polymerase high fidelity", $1 \mathrm{X}$ "high fidelity PCR buffer" (Invitrogen Brasil, Ltda., São Paulo, SP, Brasil), 2 mmol L-1 $\mathrm{MgSO}_{4}, 10$ pmol do iniciador vip5, 10 pmol do iniciador vip6, 0,2 $\mathrm{mmol} \mathrm{L}^{-1}$ de mistura de dNTP, e água destilada deionizada estéril (q.s.p $20 \mu \mathrm{L}$ ). Foram utilizadas as seguintes temperaturas e tempos de incubação: $94^{\circ} \mathrm{C}$, por $2 \mathrm{~min}$; 30 ciclos de $94^{\circ} \mathrm{C}$, por $1 \mathrm{~min} ; 53^{\circ} \mathrm{C}$, por 1 min; $68^{\circ} \mathrm{C}$, por $2 \mathrm{~min} ; 68^{\circ} \mathrm{C}$, por $5 \mathrm{~min}$; e $4^{\circ} \mathrm{C}$, até a utilização da amostra.

O gene vip $3 A$ completo, amplificado a partir do isolado I131, foi inserido no vetor pGEM-T Easy (Promega, Madison, WI, EUA), segundo instruções do fabricante. $\mathrm{O}$ produto da reação de ligação foi utilizado para transformar células competentes de Escherichia coli DH10B pelo método de choque térmico (Hanahan et al., 1983). Os clones foram sequenciados com o reagente "Big Dye Terminator" v3.1 (Applied Biosystems, Carlsbad, CA, EUA), em um sequenciador automático ABI 3100 (Applied Biosystems, Carlsbad, CA, EUA). Para obtenção da sequência completa do gene, foram utilizados iniciadores específicos com anelamento ao longo do gene (Tabela 1). A sequência-consenso do gene foi gerada com uso da ferramenta Phred/Phrap/Consed (Ewing \& Green, 1998; Ewing et al., 1998; Gordon et al., 1998) e comparada a outros genes vip3A, por

Pesq. agropec. bras., Brasília, v.48, n.9, p.1220-1227, set. 2013 DOI: 10.1590/S0100-204X2013000900005 
meio da "basic local alignment search tool" (Blast), com o algoritmo BlastX, a partir do banco de dados da National Center for Biotechnology Information (2013).

Uma sequência de nucleotídeos com 2.370 pb, que codificou 789 aminoácidos, foi submetida ao banco de dados GenBank (National Center for Biotechnology Information, 2013). Esta sequência recebeu o número de acesso JQ946639 e foi enviada ao banco de dados Bacillus thuringiensis Toxin Nomenclature (Crickmore et al., 2012), para classificação, no qual recebeu a denominação de gene vip3Aa50. Para a expressão heteróloga, o gene vip $3 A$ do isolado I131 foi subclonado no vetor pET-28a (Novagen, Itapira, $\mathrm{SP}$ ), a partir do vetor pGEM-T Easy. O vetor de expressão foi clivado com a enzima NotI (Fermentas, Saint-Rémy-les-Chevreuses, França) e desfosforilado com a enzima fosfatase alcalina (Fermentas), de acordo com as condições do fabricante. A clonagem, neste sítio de restrição, propiciou a fusão de uma hexa-histidina à porção N-terminal da proteína Vip3Aa50. Em seguida, o vetor foi purificado com o kit QIAquick PCR purification (Qiagen, Valencia, CA, EUA). O gene vip3A foi retirado do vetor pGEM-T Easy com a enzima NotI (Fermentas), visualizado em gel de agarose a $0,8 \%$, excisado do gel e purificado com o kit PureLink (Invitrogen Brasil Ltda., São Paulo, SP, Brasil). A reação de ligação do inserto ao vetor pET-28a (+) (Novagen) foi realizada em volume total de $20 \mu \mathrm{L}$, com: $100 \mathrm{ng}$ do inserto, $25 \mathrm{ng}$ do vetor, 3 U T4 DNA ligase (Promega, Madison, WI, EUA), 1X "rapid ligation buffer" e água deionizada estéril (q.s.p. $20 \mu \mathrm{L}$ ), seguida de incubação a $4^{\circ} \mathrm{C}$ por 16 horas. O produto desta reação foi utilizado para transformar, por choque térmico, células de expressão competentes de E. coli BL21 (DE3) (Hanahan et al., 1983). O DNA plasmidial dos clones foi extraído (Sambrook \& Russel, 2001), e a seleção do clone com o inserto subclonado foi feita por resistência à canamicina; a confirmação da orientação correta foi realizada por sequenciamento com o iniciador T7 (Sanger et al., 1977).

Os clones de E. coli BL21 (DE3) portadores do gene vip $3 A$ foram cultivados em meio sólido, suplementado com canamicina $\left(50 \mu \mathrm{g} \mathrm{mL}^{-1}\right)$. Uma colônia isolada foi inoculada em $20 \mathrm{~mL}$ de pré-cultura e multiplicada a $37^{\circ} \mathrm{C}$, em agitação a $250 \mathrm{rpm}$ por 16 horas. Em seguida, 1,5 mL de pré-cultura foi transferido para $250 \mathrm{~mL}$ de meio LB líquido, que continha canamicina $\left(50 \mu \mathrm{g} \mathrm{mL} \mathrm{mL}^{-1}\right)$, e foi incubado a $37^{\circ} \mathrm{C}$, a $250 \mathrm{rpm}$, até atingir D.O. ${ }_{600}$ entre $0,6-0,8$. A concentração final de $0,5 \mathrm{mmol} \mathrm{L}^{-1}$ de IPTG foi adicionada à cultura, que foi mantida a $22^{\circ} \mathrm{C}$, a $200 \mathrm{rpm}$ por 16 horas, para a indução da expressão. A temperatura utilizada na expressão da proteína Vip3Aa50 foi de $22^{\circ} \mathrm{C}$, apesar de a temperatura ideal de crescimento da bactéria E. coli ser $37^{\circ} \mathrm{C}$; a essa temperatura, a proteína seria expressa em corpos de inclusão, o que a tornaria insolúvel. Optou-se, portanto, por reduzir a temperatura para $22^{\circ} \mathrm{C}$, após a indução por IPTG; a esta temperatura, a proteína é encontrada na forma solúvel, que representa mais adequadamente a característica da proteína e facilita a sua recuperação no processo de extração. As células de E. coli BL21 (DE3) foram coletadas por centrifugação a $17.400 \mathrm{~g}$ por $20 \mathrm{~min}$. Os sedimentos foram ressuspensos em tampão-fosfato $\left(20 \mathrm{mmol} \mathrm{L}^{-1}+0,5 \mathrm{~mol} \mathrm{~L}^{-1} \mathrm{NaCl}\right.$, $\mathrm{pH} 7,4), 3 \mathrm{mg} \mathrm{mL}^{-1}$ lisozima, e $0,01 \mathrm{mg} \mathrm{mL}^{-1}$ DNAse, e incubados a $37^{\circ} \mathrm{C}$, com agitação de $100 \mathrm{rpm}$ por $30 \mathrm{~min}$. Em seguida, as amostras foram submetidas à sonicação a $60 \mathrm{~W}$ por $60 \mathrm{~s}$, por duas vezes, com $10 \mathrm{~s}$ de pausa. As amostras foram centrifugadas a $17.400 \mathrm{~g}$, a $4^{\circ} \mathrm{C}$ por $30 \mathrm{~min}$, e os sobrenadantes foram armazenados $-20^{\circ} \mathrm{C}$, até utilização.

A expressão proteica foi confirmada por meio da análise em gel SDS-PAGE a 12\%, conforme Laemmli (1970), por meio do equipamento para eletroforese vertical Mini Protean II (Bio-Rad Laboratories, Richmond, CA, EUA). Foram aplicadas alíquotas do lisado bacteriano das culturas induzida e não induzida. A concentração da proteína induzida foi quantificada por densitometria, pelo programa Bionumerics (Applied-Maths, Austin, TX, EUA).

O "Western blot" (Towbin et al., 1979) foi realizado a partir de gel SDS-PAGE a 12\%, em amostras de cultura induzida e não induzida, com o marcador "Spectra Multicolor Broad Range Protein Ladder" (Fermentas). Para a detecção da proteína Vip3Aa50, com cauda de histidina, utilizou-se o anticorpo monoclonal primário antipoli-histidina (Sigma-Aldrich, St. Louis, MO, EUA) e o anticorpo secundário anti-IgG conjugado com peroxidase (GE Health Care Bio-Sciences, Piscataway, NJ, EUA), para o reconhecimento do anticorpo primário ligado à proteína. A revelação foi realizada com Sigmafast DAB (Sigma-Aldrich, St. Louis, MO, EUA).

Nos bioensaios para avaliação da toxicidade da proteína Vip3Aa50, foram utilizadas larvas neonatas, 
provenientes de criação massal (SGS Gravena Ltda., Jaboticabal, SP). Os bioensaios foram realizados em condições climáticas controladas: temperatura de $25 \pm 2^{\circ} \mathrm{C}$, umidade relativa do ar de $70 \% \pm 10 \%$, e luminosidade de 14 horas de luz por 10 horas de escuro.

A pró-toxina Vip3Aa50 obtida do isolado I131 de B. thuringiensis foi diluída em solução tampão-fosfato $20 \mathrm{mmol} \mathrm{L}^{-1}$, em volume de $50 \mu \mathrm{L}$, e aplicada sobre a dieta artificial (Praça et al., 2004), em placas de poliestireno de 128 poços, nos quais foi colocada uma lagarta neonata por poço. Avaliaram-se as concentrações $0,5,15,30,50,150,500$ e $1.500 \mathrm{ng} \mathrm{cm}^{-2}$, para $S$. frugiperda, e 0, 12, 25, 50, 100, 200 e 1.000 ng cm$~^{-2}$, para $A$. gemmatalis. Para ambas as espécies, forma aplicados $50 \mu \mathrm{L}$ de tampão-fosfato $20 \mathrm{mmol} \mathrm{L}^{-1}$, como controle negativo.

Utilizou-se o delineamento experimental inteiramente casualizado, com quatro repetições e 16 lagartas por repetição. A mortalidade foi avaliada no sétimo dia após a exposição das lagartas à dieta com a proteína inseticida vegetativa. As concentrações letais para 50 e $90 \%$ das lagartas $\left(\mathrm{CL}_{50}\right.$ e $\left.\mathrm{CL}_{90}\right)$ foram estimadas por meio da análise "probit", com o programa de estatística Polo-PC (LeOra Software, Berkeley, CA, EUA).

\section{Resultados e Discussão}

A sequência de aminoácidos obtida da expressão do gene vip3Aa50 apresentou $99 \%$ de similaridade com as sequências Vip3Aa7, Vip3Aa10, Vip3Aa11, Vip3Aa12, Vip3Aa15, Vip3Aa21, Vip3Aa33, Vip3Aa34, Vip3Aa36 e Vip3Aa37, depositadas nos bancos de dados GenBank (National Center for Biotechnology Information, 2013) e Bacillus thuringiensis Toxin Nomenclature (Crickmore et al., 2012). As diferenças ocorreram por substituições dos aminoácidos $\mathrm{Thr}^{2}$ por Asn e de Asp $^{80}$ por Asn.

A sequência de aminoácidos da proteína Vip3Aa50 apresentou 99\% de similaridade com a proteína Vip3Aa1. As substituições de bases na sequência de nucleotídeos do gene levaram à troca dos aminoácidos $\mathrm{Thr}^{2}$ por Asn, Asp ${ }^{80}$ por Asn, Lys ${ }^{284}$ por Cys. A sequência obtida apresentou, ainda, $98 \%$ de similaridade com a proteína Vip3Aa14, cujo gene foi sequenciado a partir de uma linhagem de B. thuringiensis var. tolworthi. As substituições de aminoácidos, neste caso, levaram à troca dos seguintes aminoácidos: $\mathrm{Thr}^{2}$ por Asn; $\mathrm{Asp}^{80}$ por Asn; Glu ${ }^{214}$ por Gly; Thr ${ }^{220}$ por Pro; Phe ${ }^{274}$ por Ser;
$\mathrm{Ala}^{280}$ por Leu; $\mathrm{Leu}^{323}$ por Pro; $\mathrm{Lle}^{358}$ por Val; $\mathrm{Cys}^{401}$ por Gly; Glu ${ }^{406}$ por Gly; Cys ${ }^{407}$ por Pro; Thr ${ }^{411}$ por Pro; Ser ${ }^{536}$ por Lys; $\mathrm{Asn}^{633}$ por Thr; $\mathrm{Met}^{755}$ por Lle; $\mathrm{Phe}^{760}$ por Leu; Gln ${ }^{761}$ por Gly; Tyr $^{776}$ por Asn; e His ${ }^{782}$ por Lys.

As substituições de aminoácidos evidenciam a presença de novos alelos da classe Vip3Aa (Crickmore et al., 1998). A alteração de aminoácidos pode causar efeito significativo sobre a atividade inseticida das toxinas, conforme observado por Shen et al. (2009). Estes autores relataram que as poucas substituições de aminoácidos nas proteínas Vip3Aa26 e Vip3Aa27 acarretaram diferentes atividades inseticidas. A proteína Vip3Aa27 apresentou potencial inseticida contra as espécies Trichoplusia ni, Spodoptera exigua e Helicoverpa armigera; a Vip3Aa26 somente apresentou atividade contra as lagartas da espécie $T$. ni, o que indica que proteínas de mesma subclasse podem expressar mecanismos de ação diferentes.

A região N-terminal das proteínas Vip3 é altamente conservada; assim, as diferenças entre as sequências de aminoácidos observadas nas proteínas desta família encontram-se principalmente na região C-terminal (Wu et al., 2007). A proteína Vip3Aa50 apresenta poucas mutações em sua região $\mathrm{N}$-terminal, em comparação a outras proteínas Vip3Aa, o que também foi observado por Sauka et al. (2013), para as proteínas Vip3Aa40 e Vip3Aa41.

A diversidade observada na família de proteínas Vip é atribuída a mutações, que ampliaram o espectro de ação sobre os insetos da ordem Lepidoptera (Wu et al., 2007). Assim, as mutações observadas na proteína Vip3Aa50 podem ter resultado em um espectro de ação diferente daquele que é apresentado por outras proteinas da subclasse Vip3Aa. Selvapandiyan et al. (2001) realizaram a deleção de códons na região $\mathrm{N}$-terminal e na região $\mathrm{C}$-terminal do gene vip $3 A \mathrm{a} 9 \mathrm{em}$ ensaios isolados. A expressão heteróloga das proteínas em E. coli, permitiu constatar a alteração da atividade inseticida da proteína. A deleção de aminoácidos na região $\mathrm{N}$-terminal não afetou a toxicidade contra as larvas de Chilo partellus, mas reduziu a toxicidade contra a Spodoptera litura. Além disso, a deleção de aminoácidos da região $\mathrm{C}$-terminal reduziu a toxicidade da proteína a C. partellus e a extinguiu contra a S. litura. Estes resultados indicam uma resposta individual de cada espécie à ação de uma dada toxina, conforme sua composição de aminoácidos. 
O gene vip3Aa50 sequenciado foi subclonado com sucesso, a partir do vetor pGEM-T Easy no vetor de expressão pET-28a $(+)$. A expressão proteica na cultura induzida foi confirmada pela formação de uma banda de aproximadamente $88,5 \mathrm{kDa}$, o que era esperado para a proteína Vip3Aa50, conforme descrito por Estruch et al. (1996) (Figura 1). A expressão da proteína Vip3Aa50 foi confirmada no "Western blot" (Figura 2). O reconhecimento da hexa-histidina ligada ao N-terminal da proteína Vip3Aa50 propiciou a reação com o anticorpo antipoli-histidina e evidenciou a expressão em ambas as culturas, que foi mais pronunciada na cultura induzida. A expressão basal do gene vip3Aa50 na cultura não induzida se justifica pelo fato de ocorrer, mesmo na ausência de IPTG,

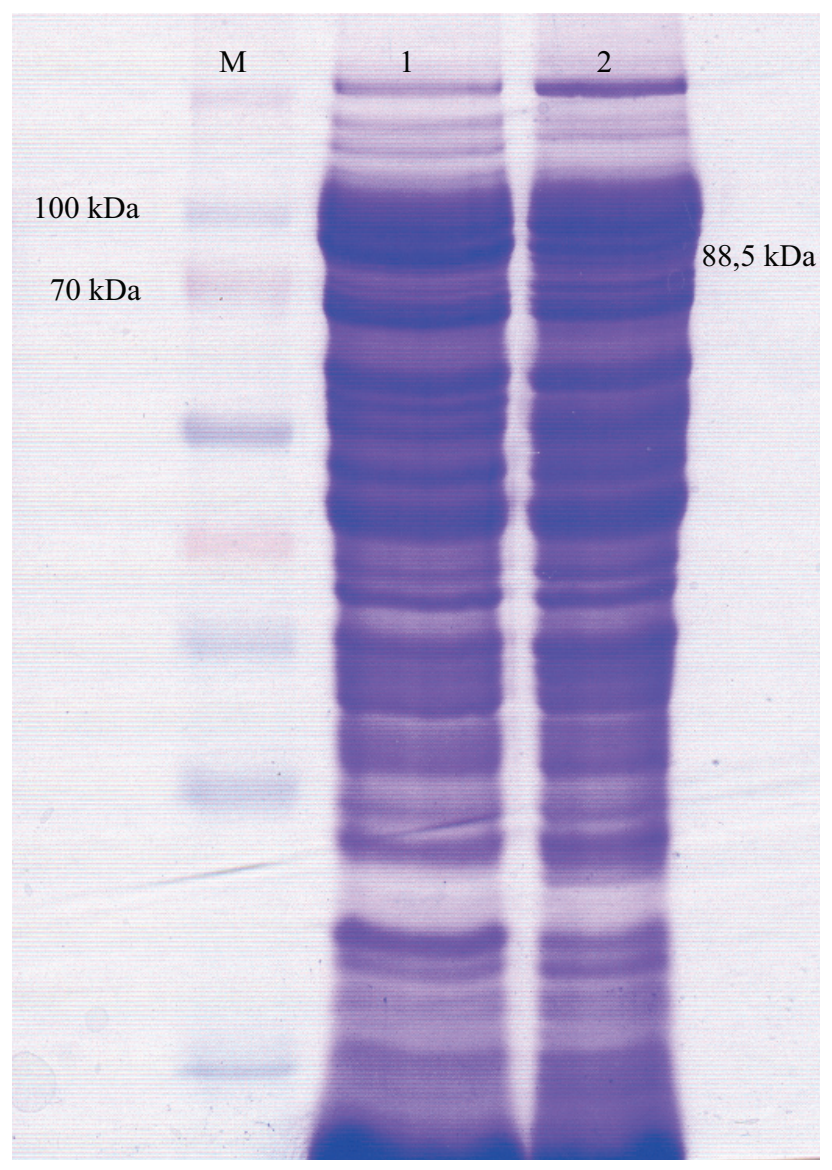

Figura 1. Gel SDS-PAGE do lisado bacteriano de Escherichia coli, portadora do vetor pET-28a com o gene vip3Aa50. M, marcador de massa molecular (kDa); 1, lisado de $E$. coli obtido da cultura induzida; 2, lisado de $E$. coli obtido da cultura não induzida, com uma proteína de aproximadamente $88,5 \mathrm{kDa}$. uma indução ocasionada pela expressão da T7 RNA polimerase do promotor lacUV5, presente na cepa bacteriana E. coli BL 21 (DE3), utilizada como hospedeira para expressão da proteína Vip3Aa50 (Studier \& Moffatt,1986).

A pró-toxina Vip3Aa50 apresentou alta toxicidade para ambas as espécies de lagartas testadas (Tabela 2). Porém, pela avaliação dos valores de $\mathrm{CL}_{50}$ e $\mathrm{CL}_{90}$, verificou-se que as lagartas da espécie $A$. gemmatalis foram mais suscetíveis que as de $S$. frugiperda. A atividade inseticida da proteína Vip3Aa50, dada pela $\mathrm{CL}_{50}$, foi cerca de quatro vezes maior contra A. gemmatalis. Para $\mathrm{CL}_{90}$, a diferença foi ainda mais pronunciada, com eficácia nove vezes maior para o controle de $A$. gemmatalis. O tratamento controle

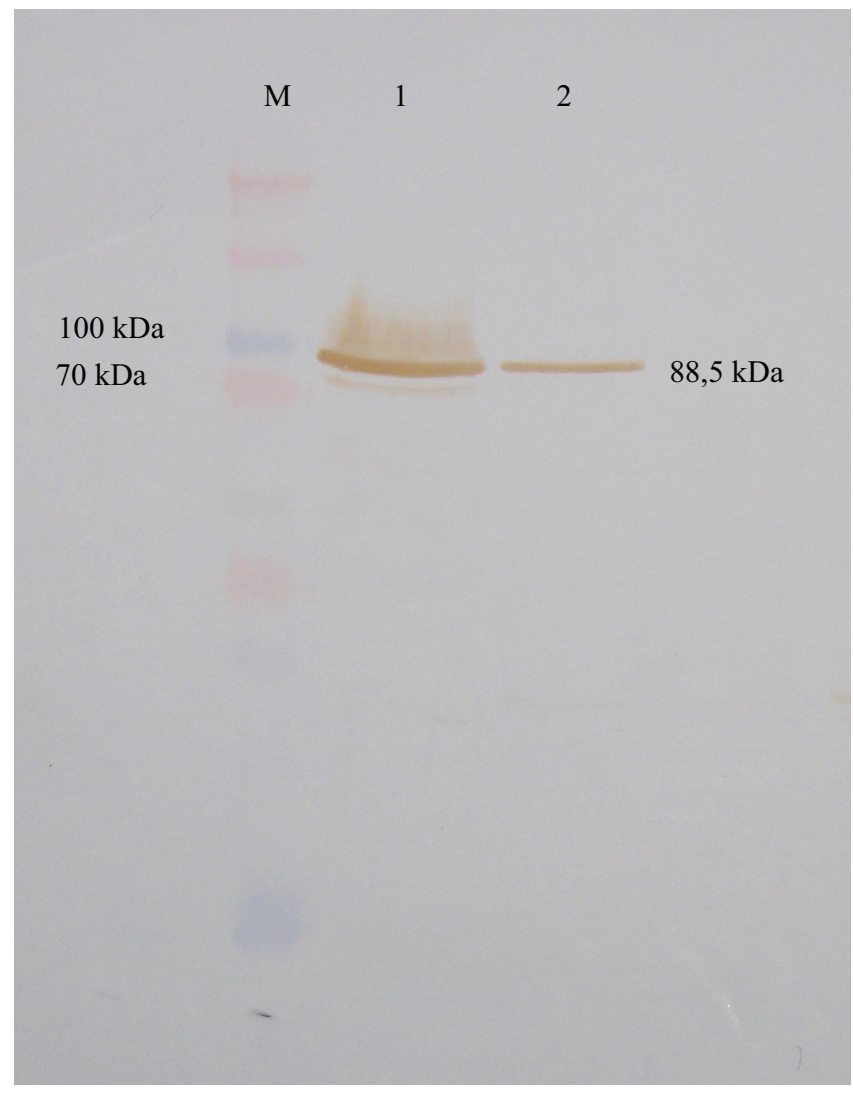

Figura 2. "Western blot" do lisado bacteriano de E. coli portadora do vetor pET-28a com o gene vip3Aa50. M, marcador de massa molecular $(\mathrm{kDa}) ; 1$, lisado de E. coli obtido da cultura induzida; 2, lisado de E. coli obtido da cultura não induzida. Observa-se em 1 e 2 a reação da proteína de aproximadamente $88,5 \mathrm{kDa}$ com o anticorpo anti-6xHis. 
negativo, com tampão-fosfato $20 \mathrm{mmol} \mathrm{L}^{-1}$, não causou mortalidade às larvas de nenhuma das espécies.

Resultados semelhantes foram observados por outros autores para S. frugiperda. Sena et al. (2009) que relataram $\mathrm{CL}_{50}$ de $49,3 \mathrm{ng} \mathrm{cm}^{-2}$ da proteína Vip3A, próxima à encontrada no presente estudo. Chakroun et al., (2012) observaram $\mathrm{CL}_{50}$ de $340 \mathrm{ng} \mathrm{\textrm {cm } ^ { - 2 }}$ da pró-toxina Vip3Aa16, quatro vezes superior à encontrada no presente estudo, e dentro dos limites da $\mathrm{CL}_{90}$ aqui descrita. Fang et al. (2007) obtiveram maior eficácia de Vip3Aa1, com $\mathrm{CL}_{50}$ de $6,9 \mathrm{ng} \mathrm{cm}^{-2}$ para a Vip3Aa1, valor cerca de 11 vezes menor do que os obtidos aqui.

A toxicidade das proteínas às espécies de insetos-praga pode variar em razão de diferentes fatores, como o mecanismo de ativação da pró-toxina em toxina (Chakroun et al., 2012), ou alterações nos receptores da membrana do epitélio intestinal do inseto (Ferré \& Van Rie, 2002). A proteólise de pró-toxinas com o suco gástrico de larvas de diferentes espécies pode acarretar diferenças no tempo de ativação, tamanho de fragmentos gerados in vitro e na atividade inseticida das toxinas in vivo, conforme o observado por Chakroun et al. (2012) em lagartas de S. frugiperda e $S$. exígua, e por Abdelkefi-Mesrati et al. (2011) em lagartas Anagasta kuehniella e Spodoptera littoralis. A ação da toxina pode ser diferenciada no receptor, de acordo com Bergamasco et al. (2013), com a parcial competição das proteínas Vip3Aa e Cry1Ia10 em Spodoptera eridania.

Sena et al. (2009) analisaram a toxicidade e a interação de ligação das proteínas Vip3Aa, Vip3Af, Cry1Ab e Cry1Fa a vesículas de membrana de borda, na escova do epitélio intestinal (BBMVs) de $S$. frugiperda. Nos ensaios de toxicidade, os autores constataram que as proteínas Vip3 foram mais efetivas

Tabela 2. Suscetibilidade ${ }^{(1)}$ de larvas neonatas de Spodoptera frugiperda e Anticarsia gemmatalis à pró-toxina Vip3Aa50.

\begin{tabular}{lcccc}
\hline Espécie & $\mathrm{CL}_{50}$ & $\mathrm{CL}_{90}$ & b \pm erro-padrão & $\mathrm{X}^{2}$ \\
& $\left.-------\mathrm{ng} \mathrm{cm}^{-2}\right)---------$ & & \\
\hline S. frugiperda & 79,6 & 547,5 & $1,5 \pm 0,2$ & 1,660 \\
& $(51,1-129,6)$ & $(289,4-1630,8)$ & & \\
A. gemmatalis & 20,3 & 62,7 & $2,6 \pm 0,5$ & 0,738 \\
& $(14,5-27,5)$ & $(43,5-116,8)$ & & \\
\hline
\end{tabular}

(1) Avaliada por meio das concentrações letais para 50 e $90 \%$ das lagartas $\left(\mathrm{CL}_{50} \mathrm{e} \mathrm{CL}_{90}\right)$, estimadas por meio da análise probit. Valores entre parênteses referem-se ao intervalo de confiança, a $95 \%$ de probabilidade. b, coeficiente angular da reta; $\mathrm{X}^{2}$, valores do teste qui-quadrado, entre a mortalidade esperada com o uso das proteínas e a observada no tratamento controle. no controle das lagartas do que as proteínas Cry1, e os valores de $\mathrm{CL}_{50}$ foram de 49,3 $\mathrm{ng} \mathrm{cm}^{-2}$ para Vip3Aa, de $21 \mathrm{ng} \mathrm{cm}^{-2}$ para Vip3Af, de $867 \mathrm{ng} \mathrm{cm}^{-2}$ para Cry1 Ab e de $170 \mathrm{ng} \mathrm{cm}^{-2}$ para Cry1Fa. Estes resultados são corroborados pelos encontrados no presente trabalho, em que a $\mathrm{CL}_{50}$ da proteína Vip3Aa50 foi bem superior à encontrada pelo autor para a Cry1 $\mathrm{Ab}$ e Cry1Fa.

Não foram encontrados estudos com proteínas Vip3A na lagarta-da-soja. O controle desta espécie foi descrito principalmente com uso de isolados que expressavam as toxinas Cry1 (Gobatto et al., 2010), Cry2 e Cry9 (Fiuza et al., 2012).

Estudos referentes à composição, à função (avaliada por deleções ou fusão de aminoácidos) e ao efeito tóxico das proteínas Vip3 podem contribuir para aumentar a eficácia do controle de pragas e retardar a seleção de resistência a toxinas de $B$. thuringiensis. A elevada atividade inseticida da proteína Vip3Aa50 do isolado I131, relatada no presente estudo, torna este isolado um excelente candidato a fonte do gene vip $3 \mathrm{~A}$, para emprego em plantas transgênicas piramidizadas com genes cry.

\section{Conclusões}

1. O gene vip3A sequenciado é um novo gene da classe vip3, que apresenta 99\% de similaridade com os já descritos na classe das proteínas inseticidas vegetativas.

2. A proteína Vip3Aa50, proveniente do isolado I131 de Bacillus thuringiensis, é expressa na forma ativa e tóxica a larvas neonatas de Spodoptera frugiperda e Anticarsia gemmatalis.

3. As lagartas de $A$. gemmatalis são mais sensíveis à toxina Vip3Aa50 do que as de $S$. frugiperda.

\section{Referências}

ABDELKEFI-MESRATI, L.; BOUKEDI, H.; CHAKROUN, M.; KAMOUN, F.; AZZOUZ, H.; TOUNSI, S.; ROUIS, S.; JAOUA, S. Investigation of the steps involved in the difference of susceptibility of Ephestia kuehniella and Spodoptera littoralis to the Bacillus thuringiensis Vip3Aa16 toxin. Journal of Invertebrate Pathology, v.107, 198-201, 2011. DOI: 10.1016/j. jip.2011.05.014.

BERGAMASCO, V.B.; MENDES, D.R.P.; FERNANDES, O.A.; DESIDÉRIO, J.A.; LEMOS, M.V.F. Bacillus thuringiensis Cry1Ia10 and Vip3Aa protein interactions and their toxicity in Spodoptera spp.(Lepidoptera). Journal of Invertebrate Pathology, v.112, p.152-158, 2013. DOI: 10.1016/j.jip.2012.11.011. 
CHAKROUN, M.; BEL, Y.; CACCIA S.; ABDELKEFI-MESRATI, L.; ESCRICHE, B.; FERRÉ, J. Susceptibility of Spodoptera frugiperda and $S$. exigua to Bacillus thuringiensis Vip3Aa insecticidal protein. Journal of Invertebrate Pathology, v.110, p.334-339, 2012. DOI: 10.1016/j. jip.2012.03.021.

CRICKMORE, N.; ZEIGLER, D.R.; FEITELSON, J.; SCHNEPF, E.; VAN RIE, J.; LERECLUS, D.; BAUM, J.; DEAN, D.H. Revision of the nomenclature for the Bacillus thuringiensis pesticidal crystal proteins. Microbiology and Molecular Biology Reviews, v.62, p.807-813, 1998.

CRICKMORE, N.; ZEIGLER, D.R.; SCHNEPF, E.; VAN RIE, J.; LERECLUS, D.; BAUM, J.; BRAVO, A.; DEAN, D.H. Bacillus thuringiensis toxin nomenclature. Available at: $<\mathrm{http}: / / \mathrm{www}$. lifesci.sussex.ac.uk/Home/Neil_Crickmore/Bt/>. Accessed on: 20 Apr. 2012.

ESTRUCH, J.J.; WARREN, G.W.; MULLINS, M.A.; NYE, G.J.; CRAIG, J.A.; KOZIEL, M.G. Vip3A, a novel Bacillus thuringiensis vegetative insecticidal protein with a wide spectrum of activities against lepidopteran insects. Proceedings of the National Academy of Sciences of the United States of America, v.93, p.5389-5394, 1996. DOI: 10.1073/pnas.93.11.5389.

EWING, B.; GREEN, P. Base-calling of automated sequencer traces using phred. II - Error probabilities. Genome Research, v.8, p.186-194, 1998

EWING, B.; HILlIER, L.; WENDL, M.C.; GREEN, P. Base-calling of automated sequencer traces using phred. I. Accuracy assessment. Genome Research, v.8, p.175-185, 1998. DOI: $10.1101 /$ gr.8.3.175.

FANG, J.; XU, X.; WANG, P.; ZHAO, J.Z.; SHELTON, A.M.; CHENG, J.; FENG, M.G.; SHEN, Z. Characterization of chimeric Bacillus thuringiensis Vip3 toxins. Applied and Environmental Microbiology, v.73, p.956-961, 2007. DOI: 10.1128/ AEM.02079-06.

FERRÉ, J.; VAN RIE, J. Biochemistry and genetics of insect resistance to Bacillus thuringiensis. Annual Review of Entomology, v.47, p.501-533, 2002. DOI: 10.1146/annurev. ento.47.091201.145234.

FIÚZA, L.M.; BERLITZ, D.L. Produtos de Bacillus thuringiensis, registro e comercialização. Biotecnologia Ciência e Desenvolvimento, n.38, p.58-60, 2009.

FIUZA, L.M.; SCHÜENEMANN, R.; PINTO, L.M.N.; ZANETTINI, M.H.B. Two new Brazilian isolates of Bacillus thuringiensis toxic to Anticarsia gemmatalis (Lepidoptera: Noctuidae). Brazilian Journal of Biology, v.72, p.363-369, 2012. DOI: $10.1590 / \mathrm{S} 1519-69842012000200018$.

GOBATTO, V.; GIANI, S.G.; CAMASSOLA, M.; DILLON, A.J.P.; SPECHT, A.; BARROS, N.M. Bacillus thuringiensis isolates entomopathogenic for Culex quinquefasciatus (Diptera: Culicidae) and Anticarsia gemmatalis (Lepidoptera: Noctuidae). Brazilian Journal of Biology, v.70, p.1039-1046, 2010. DOI: 10.1590/S1519-69842010000500018.

GORDON, D.; ABAJIAN, C.; GREEN, P. Consed: a graphical tool for sequence finishing. Genome Research, v.8, p.195-202, 1998. DOI: $10.1101 /$ gr.8.3.195.
HANAHAN, D. Studies on transformation of Escherichia coli with plasmids. Journal of Molecular Biology, v.166, p.557-580, 1983. DOI: 10.1016/S0022-2836(83)80284-8.

LAEMMLI, U.K. Cleavage of structural proteins during assembly of the head of bacteriophage T4. Nature, v.227, p.680-681, 1970. DOI: $10.1038 / 227680 \mathrm{a} 0$.

LEE, M.K.; MILES, P.; CHEN, J.S. Brush border membrane binding properties of Bacillus thuringiensis Vip3A toxin to Heliothis virescens and Helicoverpa zea midguts. Biochemical and Biophysical Research Communications, v.339, p.1043-1047, 2006. DOI: 10.1016/j.bbrc.2005.11.112.

LETOWSKI, J.; BRAVO, A.; BROUSSEAU, R.; MASSON, L. Assessment of cryl gene contents of Bacillus thuringiensis strains by use of DNA microarrays. Applied and Environmental Microbiology, v.71, p.5391-5398, 2005. DOI: 10.1128/ AEM.71.9.5391-5398.2005.

LIU, J.; SONG, F.; ZHANG, J.; LIU, R.; HE, K.; TAN, J.; HUANG, D. Identification of vip3A-type genes from Bacillus thuringiensis strains and characterization of a novel vip3A-type gene. Letters in Applied Microbiology, v.45, p.432-438, 2007. DOI: 10.1111/j.14 72-765X.2007.02217.X.

LOGUERCIO L.L.; BARRETO M.L.; ROCHA T.L.; SANTOS C.G.; TEIXEIRA F.F.; PAIVA, E. Combined analysis of supernatant-based feeding bioassays and PCR as a first-tier screening strategy for Vip-derived activities in Bacillus thuringiensis strains effective against tropical fall armyworm. Journal of Applied Microbiology, v.93, p.269-277, 2002. DOI: 10.1046/j.1365-2672.2002.01694.x.

MARUCCI, S.C. Seleção e caracterização de novos genes vip3A: genes inseticidas de segunda geração de Bacillus thuringiensis. 2010. 64p. Dissertação (Mestrado) - Universidade Estadual Paulista, Jaboticabal.

MENDES, S.M.; MARUCCI, R.C.; MOREIRA, S.G.; WAQUIL, J.M. Milho Bt: avaliação preliminar da resistência de híbridos comerciais à lagarta-do-cartucho, Spodoptera frugiperda (J. E. Smith, 1797). Sete Lagoas: Embrapa Milho e Sorgo, 2008. 8p. (Embrapa Milho e Sorgo. Comunicado técnico, 157).

MENDONÇA, E.G. de; VISÔTTO, L.E.; COSTA, N.C.S.; RIBEIRO, F.R.; OLIVEIRA, J.A. de; OLIVEIRA, M.G. de A. Caracterização enzimática de isoformas de cisteíno protease de Anticarsia gemmatalis (HÜBNER, 1818). Ciência e Agrotecnologia, v.35, p.446-454, 2011. DOI: 10.1590/ S1413-70542011000300002.

MONNERAT, R.; BRAVO, A. Proteínas bioinseticidas produzidas pela bactéria Bacillus thuringiensis: modo de ação e resistência. In: MELO I.S.; AZEVEDO, J.L. (Ed.). Controle biológico. Jaguariúna: Embrapa Meio Ambiente, 2000. p.163-200.

NATIONAL CENTER FOR BIOTECHNOLOGY INFORMATION. GenBank. 2013. Available at: <http://www. ncbi.nlm.nih.gov/genbank/>. Accessed on: 27 Mar. 2013.

PRAÇA, L.B.; BATISTA, A.C.; MARTINS, É.S.; SIQUEIRA, C.B.; DIAS, D.G. de S.; GOMES, A.C.M.M.; FALCÃO, R.; MONNERAT, R.G. Estirpes de Bacillus thuringiensis efetivas contra insetos das ordens Lepidoptera, Coleoptera e Diptera. Pesquisa Agropecuária Brasileira, v.39, p.11-16, 2004. DOI: 10.1590/S0100-204X2004000100002. 
SAMBROOK, J.; RUSSEL, D.W. Molecular cloning: a laboratory manual. $3^{\text {rd }}$ ed. Nova York: Cold Spring Harbor, 2001. 250p.

SAMPURNA, S.; MAITI, M.K. Molecular characterization of a novel vegetative insecticidal protein from Bacillus thuringiensis effective against sap-sucking insect pest. Journal of Microbiology and Biotechnology, v.21, p.937-946, 2011. DOI: 10.4014/ jmb.1105.05030.

SANGER, F.; NICKLEN, S.; COULSON, A.R. DNA sequencing with chain-terminating inhibitors. Proceedings of the National Academy of Sciences, v.74, p.5463-5467, 1977. DOI: 10.1073/ pnas.74.12.5463.

SAUKA, D.H.; RODRIGUEZ, S.E.; BENINTENDE, G.B. New variants of lepidoptericidal toxin genes encoding Bacillus thuringiensis Vip3Aa proteins. Journal of Molecular Microbiology and Biotechnology, v.22, p.373-380, 2013. DOI: 10.1159/000345911.

SELVAPANDIYAN, A.; ARORA, N.; RAJAGOPAL, R.; JALALI, S.K.; VENKATESAN, T.; SINGH, S.P.; BHATNAGAR, R.K. Toxicity analysis of $\mathrm{N}$ - and C-terminus-deleted vegetative insecticidal protein from Bacillus thuringiensis. Applied and Environmental Microbiology, v.67, p.5855-5858, 2001. DOI: 10.1128/AEM.67.12.5855-5858.2001.

SENA, J.A.D.; HERNANDEZ-RODRIGUES, C.S.; FERRE, $\mathrm{J}$. Interaction of Bacillus thuringiensis Cry1 and Vip3A proteins with Spodoptera frugiperda midgut binding sites. Applied and Environmental Microbiology, v.75, p.2236-2237, 2009. DOI: 10.1128/AEM.02342-08.

SHEN, J.; HOU, M.; GUO, W. Identification and cloning of vip $3 A$ genes from isolates of Bacillus thuringiensis and their bioactivity analysis. Wei Sheng Wu Xue Bao, v.49, p.110-116, 2009.

STUDIER F.W.; MOFFATT, B.A. Use of bacteriophage T-7 RNA polymerase to direct selective high-level expression of cloned genes. Journal of Molecular Biology, v.189, p.113-130, 1986. DOI: 10.1016/0022-2836(86)90385-2.

TOWBIN, H.; STAEHETIN, A.; GORDON, J. Electrophoretic transfer of proteins from polyacrylamide gels to nitrocellulose sheets: procedure and some applications. Proceedings of the National Academy of Sciences, v.76, p.4350-4354, 1979. DOI: 10.1073/pnas.76.9.4350.

WARREN, G.W. Vegetative insecticidal proteins: novel proteins for control of corn pests. In: CAROZZI, N.B.; KOZIEL, M. (Ed.). Advances in insect control: the role of transgenic plants. London: Taylors and Francis, 1997. p.109-121. DOI: 10.1201/9780203211731.ch7.

WU, J.; ZHAO, F.; BAI, J.; DENG, G.; QIN, S.; BAO, Q. Evidence for positive Darwinian selection of Vip gene in Bacillus thuringiensis. Journal of Genetics and Genomics, v.34, p.649-660, 2007. DOI: 10.1016/S1673-8527(07)60074-5.

Recebido em 27 de março de 2013 e aprovado em 30 de agosto de 2013

Pesq. agropec. bras., Brasília, v.48, n.9, p.1220-1227, set. 2013 DOI: 10.1590/S0100-204X2013000900005 